\title{
Activity patterns, behavioural repertoires, and agonistic interactions of crayfish: A non-manipulative field study
}

\author{
Karen M. Davis \& Robert Huber ${ }^{1)}$ \\ (Department of Biological Sciences and J.P. Scott Center for Neuroscience, Mind \& \\ Behavior, Bowling Green State University, Life Sciences Building, Bowling Green, $\mathrm{OH}$ \\ 43403, USA)
}

(Accepted: 16 January 2007)

\begin{abstract}
Summary
Agonistic behaviour of crayfish has been studied extensively in laboratory settings where pairs or groups of individuals are allowed to interact within an experimental arena. Crayfish agonistic behaviour within its natural context, however, has received little attention to date. The present, non-manipulative field study explored activity patterns, behavioural repertoires, and agonistic encounters of rusty crayfish (Orconectes rusticus) during the summer months using continuous, 24-hour, underwater video recording at a series of representative field sites. Following the filming, crayfish within the vicinity of the camera site were captured and measured. Individual densities were high, reaching a maximum of 68 individuals $/ \mathrm{m}^{2}$ at some sites. Large crayfish predominantly inhabited deeper sections of the river and were mostly active at night, whereas small crayfish generally utilized the shallows and were active outside their burrows during day and dusk. Time outside their shelter was mainly used for feeding. Individuals frequently returned to the same shelter they had emerged from. Agonistic encounters were common events and generally occurred in the context of shelter acquisition or defense. Dyadic fighting progressed with escalating sequences of stereotyped aggressive acts. Furthermore, high intensities with unrestrained use of claws were seen in encounters between size-matched opponents. The results of this study allow us to root laboratory findings of crayfish aggression within a comprehensive, ethological framework and to consider ultimate consequences for individual fighting decisions and strategies.
\end{abstract}

Keywords: agonistic behaviour, activity patterns, crayfish, ethology, shelter defense.

\footnotetext{
1) Corresponding author's e-mail address:lobsterman.bgsu@ gmail.com
} 


\section{Introduction}

Decapod crustaceans are the prevalent scavengers of temperate, aquatic environments. Crayfish and many of their phylogenetic kin occur in high numbers, dominate invertebrate biomass, and play an integral role in the structuring of many aquatic communities (Cooper \& Uzmann, 1980; Miller, 1985; Momot, 1995). Populations of crayfish in Lake Ontario, for instance, reach densities of up to 20 individuals $/ \mathrm{m}^{2}$, and their presence profoundly impacts local ecology and food webs (Stewart \& Haynes, 1994). Despite their ecological importance, little is known about the natural behaviour of this group in the field. Behavioural observations are complicated by largely nocturnal habits, frequent use of shelters, and their alertness towards the presence of observers or potential predators. The present knowledge of crayfish behaviour has thus emerged largely from studies conducted under controlled laboratory settings. Such work has addressed defensive responses to predator cues (Stein \& Magnuson, 1976; Bouwma \& Hazlett, 2001; Herberholz et al., 2004), the influence of shelter and season on diel activity patterns (Westin \& Gydemo, 1988; Barbaresi \& Gherardi, 2001), and individual behaviours in social contexts including mating (Mason, 1970; Berrill \& Arsenault, 1982, 1984; Barki \& Karplus, 1999), maternal behaviour (Hazlett, 1983; Figler et al., 1997, 2001; Levi et al., 1999), and aggressive interactions (Rubenstein \& Hazlet, 1974; Huber et al., 2001a).

With highly-stereotyped behaviours (Rubenstein \& Hazlett, 1974; Huber et al., 2001a) and a uniquely accessible nervous system (Mulloney \& Hall, 1991; Tierney, 2003) crayfish have long been a favorite model for understanding basic neural orchestration of behaviour (Edwards et al., 1999; Huber et al., 2001b; Panksepp et al., 2003; Mulloney et al., 2006). Agonistic behavioural encounters in a lab setting progress in a stepwise fashion from threat displays to unrestrained combat, eventually ending with the withdrawal of one of the combatants (Rubenstein \& Hazlett, 1974; Huber et al., 2001a). Physical superiority determines most fight outcomes closely matching predictions from game theory models (Maynard Smith \& Parker, 1976; Maynard Smith, 1982; Leimar et al., 1991), where fights are resolved quickly in the presence of prominent asymmetries of body and claw size, sex, or reproductive form (Rutherford et al., 1995; Pavey \& Fielder, 1996; Guiasu \& Dunham, 1998). Furthermore, fight strategies and success appear to be influenced by factors such as availability of food and shelter (Capelli \& Hamilton, 
1984), hunger states (Hazlett et al., 1975; Stocker \& Huber, 2001), body and claw size (Rutherford et al., 1995; Schroeder \& Huber, 2001), prior residence (Ranta \& Lindström, 1992, 1993; Peeke et al., 1995; Figler et al., 2005), aggressive state (Huber \& Delago, 1998), and social experience (Bovbjerg, 1953, 1956; Issa et al.,1999; Goessmann et al., 2000). Much of this work has been conducted in the lab, and little is known about the social interactions in the field.

Field studies, in contrast, have focused predominantly on ecological aspects of crayfish biology, including life history strategies (Momot, 1967; Hamr \& Berrill, 1984; Flinders \& Magoulick, 2006), population distributions (Berrill, 1978; Guiasu et al., 1996; Usio \& Townsend, 2000), habitat use (Englund \& Kupa, 2000; Renz \& Breithaupt, 2000), and the impact of crayfish on benthic communities (Momot et al., 1978; Creed, 1994; Parkyn et al., 2001). Initial behavioural work has characterized movement patterns (Hazlett et al., 1974; Gherardi et al., 1998, 2000), diel activity (Hazlett et al., 1979; Gherardi \& Barbaresi, 2000; Gherardi et al., 2000), and mating behaviour of crayfish (Berrill \& Arsenault, 1982, 1984; Kawai \& Saito, 2001). Accounts of crayfish agonistic behaviour in the field are limited to largely anecdotal reports (Bovbjerg, 1953; Hazlett et al., 1979, Bergman \& Moore, 2003).

In addition to engaging readily in agonistic interactions with conspecifics, crayfish are cannibalistic (Alcorlo et al., 2004; Pérez-Bote, 2005), and therefore can be considered predators to other crayfish, especially smaller conspecifics. Crayfish are also subject to predation from terrestrial predators, such as mammals and birds (Correia, 2001), as well as fish and turtles (Englund \& Krupa, 2000). Different sized crayfish are rendered differentially susceptible to capture by the various predators, which will thus likely structure the prey's distribution, habitat use, and activity patterns.

The present non-manipulative field study utilized underwater video stations in a river to provide a series of continuous, 24-h windows onto the behaviour of crayfish near it. The population of crayfish present at each site was assessed subsequently with respect to distributions of size and sex. This study specifically aimed to examine differences in (1) diel activity patterns, (2) time budgets, (3) behavioural repertoires, and (4) the presence and characteristics of social interactions for individuals of different sex and sizes classes. 


\section{Materials and methods}

Study sites

This study examined the behaviour of crayfish, Orconectes rusticus, at 17 field sites on the south, middle and north branches of the Portage River (Wood County, OH, USA) between June and August 2001. The three branches of the Portage River meet in Pemberville, OH, USA and subsequently drain into Lake Erie at Port Clinton, OH, USA. This study was conducted during the summer months as a lack of visibility during spring and fall greatly limited our ability to observe crayfish in the field. The inclusion of the spring and fall mating season would presumably have shown additional reproductive components in behavioural repertoires and time budgets. The river at these sites was moderately eutrophic, tree-lined, mostly shaded, and offered abundant shelter in rocks and detritus over mud, sand or clay. Sites were selected a minimum of $200 \mathrm{~m}$ apart featuring a range of characteristics with respect to substrate type, shelter availability, and water depth. They offered a range of river widths (2.8-19.2 m), water depths (0.17-0.49 m), current speeds $(0.05-0.37 \mathrm{~m} / \mathrm{s})$, flow volumes $\left(0.126-0.613 \mathrm{~m}^{3} / \mathrm{s}\right)$, and water temperatures $\left(21-28.5^{\circ} \mathrm{C}\right)$.

\section{Study design}

At each site an under-water video camera (YCC-350 LWW-6S, CCTV System, South Korea) was mounted on a height adjustable, horizontal arm extending $1.27 \mathrm{~m}$ from a concrete base assembly at least 24 hours before the start of filming (Figure 1). The camera height was set to just below the water surface with the lens facing directly downward toward the river bottom. Red-light diodes, attached to the arm by adjustable extenders, were used to illuminate the site throughout dusk and night. The size of the view area varied with water turbidity but on average was greater during the day (mean $0.04 \mathrm{~m}^{2}$ ) than at night (mean $0.02 \mathrm{~m}^{2}$ ). Car batteries (12VDC) were used to power video camera and lighting equipment. At each site the video signal was recorded for 24 hours $(4 \times 6 \mathrm{~h}$ tapes) with a video recorder (VHS, VR602BM623, Magnavox, China) powered by a car battery and $110 \mathrm{~V}$ inverter (PW-50, Statpower, Canada). 408 hrs of video were obtained, however, due to brief periods of increased turbidity resulting in poor visibility, the usable video was limited to a total of $325 \mathrm{~h}$. 


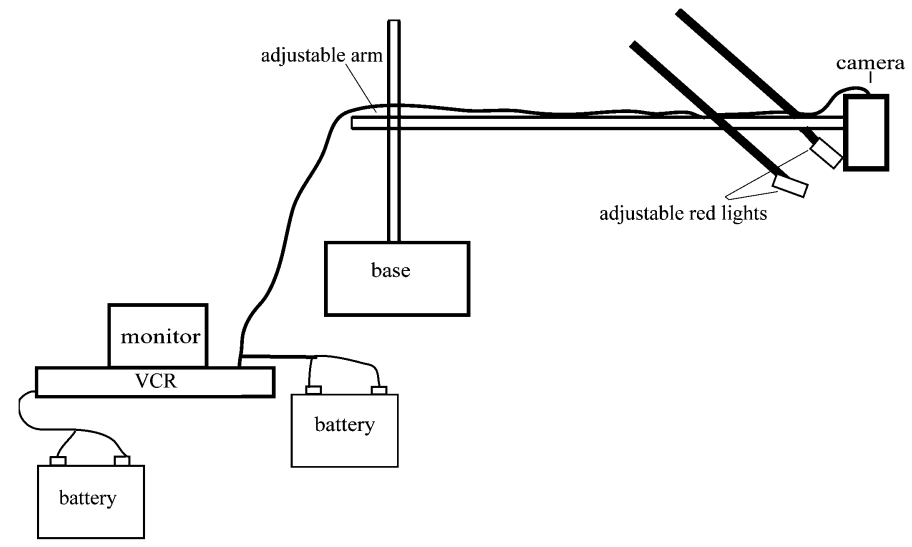

Figure 1. Setup for field recording. An underwater video camera with integrated infraredlight diodes and additional red lights for illumination at night was installed on a heightadjustable arm providing an image of the river bottom. Continuous 24-hour recording was followed by the collection of all individuals present within the immediate vicinity of the camera. Towards this goal a $5 \mathrm{~m}^{2}$ area surrounding the camera was enclosed with a seine and all crayfish contained within it were collected and measured.

\section{Sampling of crayfish populations at each site}

Following the video recording, a circular $5 \mathrm{~m}^{2}$ area around the camera was enclosed with a seine, and crayfish contained within it were collected using six sequential sweeps following a standard removal protocol (White et al., 1982; Brower et al., 1990). We characterized each individual with respect to sex, carapace length (CL), weight, claw size, evidence of past injuries including claw loss, and any other distinguishing characteristics which might serve in the identification of individuals on the video. For each sweep individuals were grouped according to sex and three size categories (small: $\mathrm{CL}<20 \mathrm{~mm}$; medium: $20 \mathrm{~mm} \leqslant \mathrm{CL}<30 \mathrm{~mm}$; large: $\mathrm{CL} \geqslant 30 \mathrm{~mm}$ ). A linear function, fitted to the decrease in number among consecutive sweeps, closely matched the data, thus validating the population sampling technique used in this study. The area under the function was used to estimate the total number of crayfish present at each site, which added 124 mostly small individuals to those actually captured (i.e., 1404 animals), for a total estimate of 1528 individuals across all 17 sites. After morphological measures had been obtained, all crayfish were returned to their respective capture site within $24 \mathrm{~h}$. 


\section{Behavioural observations}

In each hour of recording, a 15-min segment was selected at random and subjected to detailed analysis for behavioural data for a total of $80 \mathrm{~h}$ of video. Activity patterns were examined in a subset of $42 \mathrm{~h}$ restricted to those times in which turbidity was low. Each crayfish visible on screen was characterized as to its size class (small, medium, large), sex (via abdomen width and claw size), and any unique characteristics that could help in the repeated identification of individuals. Recorded were also the times at which an individual entered and exited the viewing area along with the behaviours the animal engaged in while on screen (see ethogram: Table 1). To reduce observer error all data collected from video were analyzed by the same investigator using consistent protocols. Additional observations included the following of focal individuals on its forays along the river bottom to compare their behavior with that of the crayfish recorded on tape.

All agonistic interactions visible during the full $325 \mathrm{~h}$ of viewable tape were obtained and used for a detailed analysis of fighting characteristics (see Huber et al., 2001a). Agonistic interactions began when two animals approached to within one body length and visibly reacted to each other's presence, and ended when one opponent retreated to a distance of $>1$ body length. For each interaction we recorded the identities of initiating and re-

Table 1. An ethogram of Orconectes rusticus behaviour was developed based on 80 hours of under-water video recording at 17 field sites.

\begin{tabular}{|c|c|}
\hline Behaviour & Definition \\
\hline Feeding & $\begin{array}{l}\text { stationary or walks slowly while probing the substrate or grabbing algal mats } \\
\text { or detritus with legs and/or mouth parts }\end{array}$ \\
\hline Forward & moves across the screen in forward direction \\
\hline Resting & stationary, no apparent movement aside from antennae and mouth parts \\
\hline Backward & walks backwards across the screen \\
\hline Escape & rapidly folds tail under abdomen propelling the individual up or backwards \\
\hline Agonistic & directly interacts with another individual nearby \\
\hline Digging & chelae move substrate at the base of rocks forming a cavity or depression \\
\hline Meral Spread & $\begin{array}{l}\text { displays claws, by holding claws up and out at an angle in front of head with } \\
\text { claws open, without visible opponent present }\end{array}$ \\
\hline Copulation & $\begin{array}{l}\text { male seizes, pins down and copulates or attempts to copulate with another } \\
\text { crayfish }\end{array}$ \\
\hline Grooming & $\begin{array}{l}\text { walking legs repeatedly pick over carapace, antennae, antennules, abdomen, } \\
\text { or eyes }\end{array}$ \\
\hline
\end{tabular}


treating animals, each animal's size, any size or claw asymmetries between them, and the duration and maximum intensities of resulting fight. Consecutive interactions were considered separate instances when a pause in fighting exceeded $5 \mathrm{~s}$ with a distance of $>1$ body length between them (Huber et al., 2001a).

Agonistic interactions between crayfish were analyzed from video sequences to examine similarities and differences to behaviour patterns exhibited and described previously from the laboratory (Huber et al., 2001a). The maximum intensity of agonistic interactions was coded on an ordinal scale: (0) no contest: one animal retreated from the advances of the other; (1) threat postures: both individuals contested the interaction and at least one individual used threat displays or ritualized fighting without physical contact; (2) restrained physical contact: both individuals contested the interaction and at least one individual initiated physical contact with open claws; (3) claw lock: both individuals contested the interaction and at least one individual used its claws to grab the opponent; (4) strike and rip: both individuals contested the interaction and at least one individual made unrestrained use of claws with grasping and tearing at the opponent's body and appendages.

\section{Results}

\section{Crayfish densities and activity patterns}

Crayfish populations at the 17 field sites were at high densities ranging from 6 to 68 individuals $/ \mathrm{m}^{2}$ (mean $=18$ ). Size distributions (Figure 2) varied significantly across sites (Chi-square test: $\chi_{32}^{2}=514.26, p<0.001$ ), with small individuals mostly occupying the shallow edges of the river and large crayfish predominantly inhabiting the deeper areas. No sex-specific spatial segregation was apparent (Chi-square test: $\chi_{16}^{2}=21.67, p=0.15$ ).

Detailed knowledge of the group's density and composition present at each site was used to identify the particular subset of individuals that was actually active outside their burrows at any given time. Large and mediumsized crayfish were more frequently observed on screen (Figure 3 ) than predicted based on their numbers, while small individuals were captured on screen less frequently than expected ( $G$-test: $\left.G_{12}=28640.31, p \ll 0.001\right)$. Moreover, this study identified a significant, size-specific temporal segregation in these activity patterns. Large and medium sized crayfish were observed away from shelter during dusk and night (2000-0400 h), whereas 

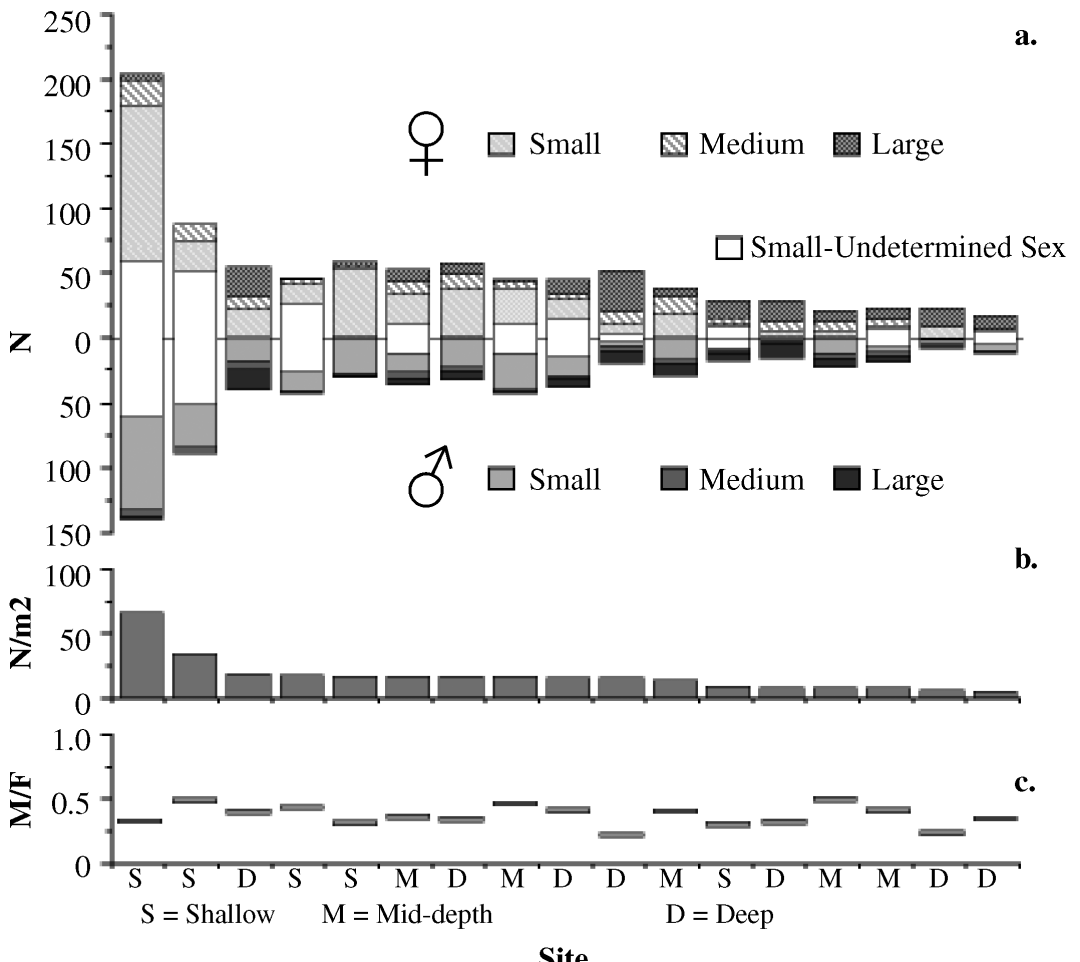

Figure 2. Summary of population characteristics. (a) The number of individuals of different size and sex classes are graphed for each site. Large (CL $\geqslant 30 \mathrm{~mm})$, medium $(20 \leqslant \mathrm{CL}<$ $30 \mathrm{~mm}$ ), and small $(\mathrm{CL}<20 \mathrm{~mm}$ ) males are represented by shaded bars below the zero line, females of these size class are plotted above the line. White bars at the center represent small individuals of undetermined sex. (b) Densities were highest at sites which predominantly featured small individuals. (c) The sex ratio was skewed toward females across all sites. The line at each site represents the number of males to females. Each site is labeled as shallow

$(\mathrm{S} \leqslant 0.28 \mathrm{~m})$, mid-depth $(0.28 \mathrm{~m}<\mathrm{M}<0.32 \mathrm{~m})$, deep $(\mathrm{D} \geqslant 0.32 \mathrm{~m})$ along the $x$ axis.

small individuals appeared mostly active at all other times, with a main peak between afternoon and dusk (1200-2000 h) (Figure 3).

\section{Crayfish behaviour}

A quantitative behavioural analysis was conducted on an 80-hour subset of videotape containing 989 observations of individuals (Figure 4). Crayfish largely traveled singly through the field of view, grazing on algal mats and detritus, and capturing invertebrate prey (Figure 4). Some recognized individual crayfish with distinctive morphological characteristics crossed the 


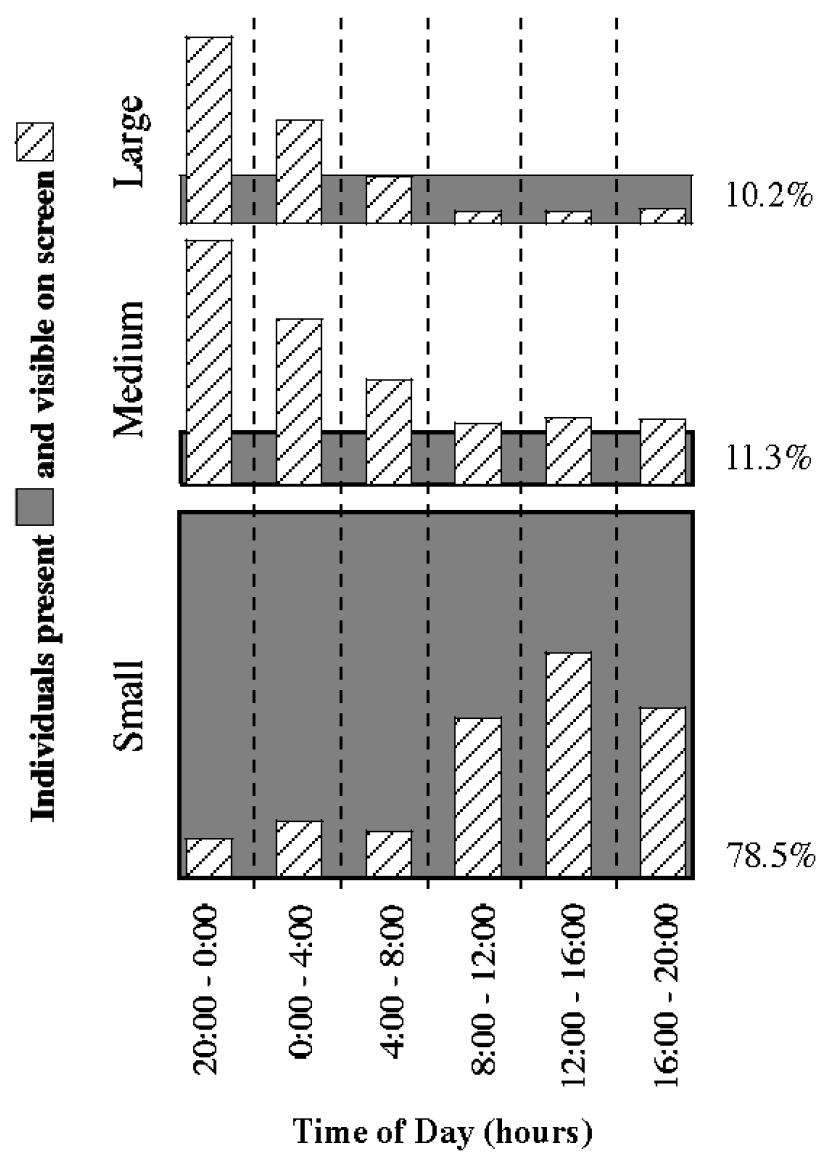

Figure 3. Activity patterns differ with size. Shaded backgrounds represent the relative proportion of individuals of small (78.5\%), medium (11.3\%), and large (10.2\%) size classes present at seven recording sites (the overall percentages are draw from the overall distribution of crayfish that were collected at each site). The bars indicate the relative number of individuals observed outside their shelters during different time periods (these percentages are scaled to $100 \%$ from the activity pattern video for each time period). This graph represents a mapping of the activity pattern data over the population data, both of which have been separately scaled to percentages as a standard unit for comparison.

field of view repeatedly over the duration of several hours, however, many others were seen only once. Entrances to shelters were included in the view area at most sites, and never appeared to be occupied by more than a single crayfish at a time. Individual residents, present in 11 of the 17 sites, repeatedly emerged from, returned to, and defended a specific shelter. Crayfish 


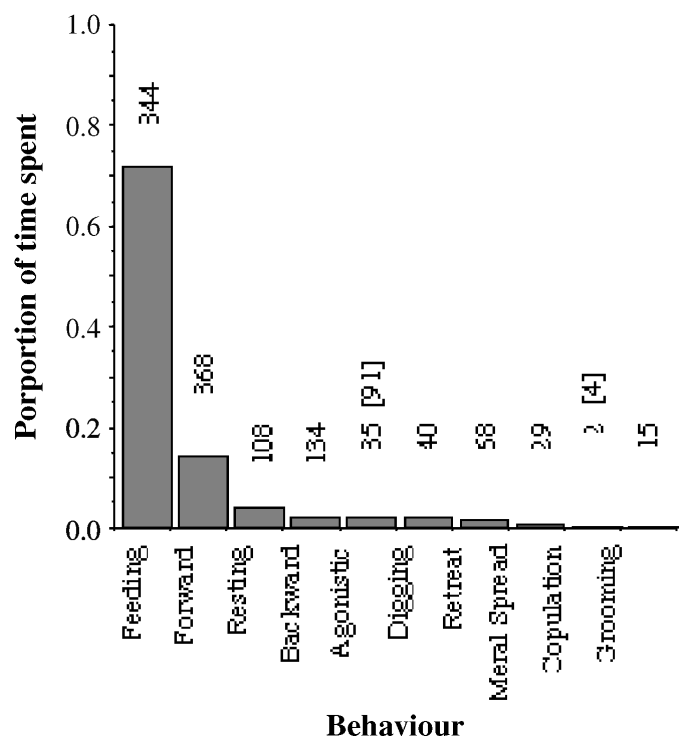

Figure 4. Behavioral repertoires of visible crayfish. The graph summarizes the proportion of time when crayfish were engaged in different behavioural activities (see Ethogram, Table 1). The numbers above the bars represent total counts for each behaviour during $80 \mathrm{hrs}$ of video recording.

frequently entered the viewing area, or exited the viewing area via escape behaviour (tail-flips) in reaction to unidentified threats. On several occasions, however, strong escape responses occurred immediately before potential heterospecific predators crossed the area of view. A snapping turtle (Chelyda serpentina) was directly observed lunging and snapping at a few large crayfish and a number of different species of fish appeared to be passing the field of view hunting for crayfish. At these times most residents retreated to their shelters and small crayfish hid from view, while several larger crayfish remained on screen and oriented towards the predator with a display of meral spread (Table 1).

Opportunities for documenting social interactions only existed in instances where multiple individuals concurrently were captured on screen. Based on the probability of viewing an animal on screen $(p=0.35)$, expected probabilities for viewing multiple crayfish at a time could be obtained. Without interference of each others movements, conditions for social interactions should be present at a probability of 0.129 (i.e., the combined probabilities for two $(p=0.123)$, three $(p=0.004)$, and more individuals 
( $p=0.002)$ on screen at a time). The video records, however, contained significantly fewer instances of multiple animals on screen than predicted by chance alone (One-tailed paired $t$-test: $t_{17}=-3.307 ; p<0.002$ ) suggesting the presence of social agonism towards conspecifics within the frame of view $\left(0.03 \mathrm{~m}^{2}\right)$. This is further evidenced by the presence of 95 dyadic, agonistic encounters in $325 \mathrm{~h}$ of video. 95 dyadic agonistic encounters in $325 \mathrm{~h}$ indicate a high level of agonism between crayfish in the field. Eleven fights were directly within the context of shelter acquisition and defense. Moreover, four encounters between males and females progressed to copulatory behaviour demonstrating the presence of this behaviour in Orconectes rusticus outside of traditional fall and spring breeding seasons. Since the mating behaviour occurred outside the traditional breeding season, gonopodia transmission may not have occurred.

Dyadic encounters in the field utilized a series of stereotyped behaviour patterns closely resembling those reported from laboratory studies, and levels of fighting intensity were recorded. Fight duration, lasting an average of $23.7 \mathrm{~s}$, proved a powerful predictor of a fight's maximum intensity and thus supported fight escalation with step-wise increases in intensity levels over time (log-transformed duration; Logistic regression: $\chi_{1}^{2}=45.09$; $p<0.001 ; r^{2}=0.19 ; N=91$; Figure 5). Fight progress and its outcome were strongly contingent on the extent of size asymmetries, where fighting was resolved quickly in pairs with a large mismatch and, in its absence, progressed to higher levels of intensity, including unrestrained combat (Figure 6). Specifically, the presence of size differences determined both fight duration (log-transformed duration; ANOVA: $F_{1,2}=25.76, p<0.05$ ) and maximum intensity reached (Chi-square test: $\chi_{8}^{2}=25.63, p<0.01$ ). The longest, most intense fights occurred during the acquisition and defense of shelters. Throughout the study period, the incidence of crayfish interactions increased with crayfish site density (Pearson's correlation: $p<0.001$, $\rho=0.78, N=95$ ). Consistent with the results of video recordings, independent observations of focal crayfish confirmed that individuals frequently engaged and displaced smaller conspecifics.

\section{Discussion}

In his classic paper, Herrick (1909) described lobsters, close kin to crayfish, as "a solitary, aggressive animal in its natural habitat". The present study 


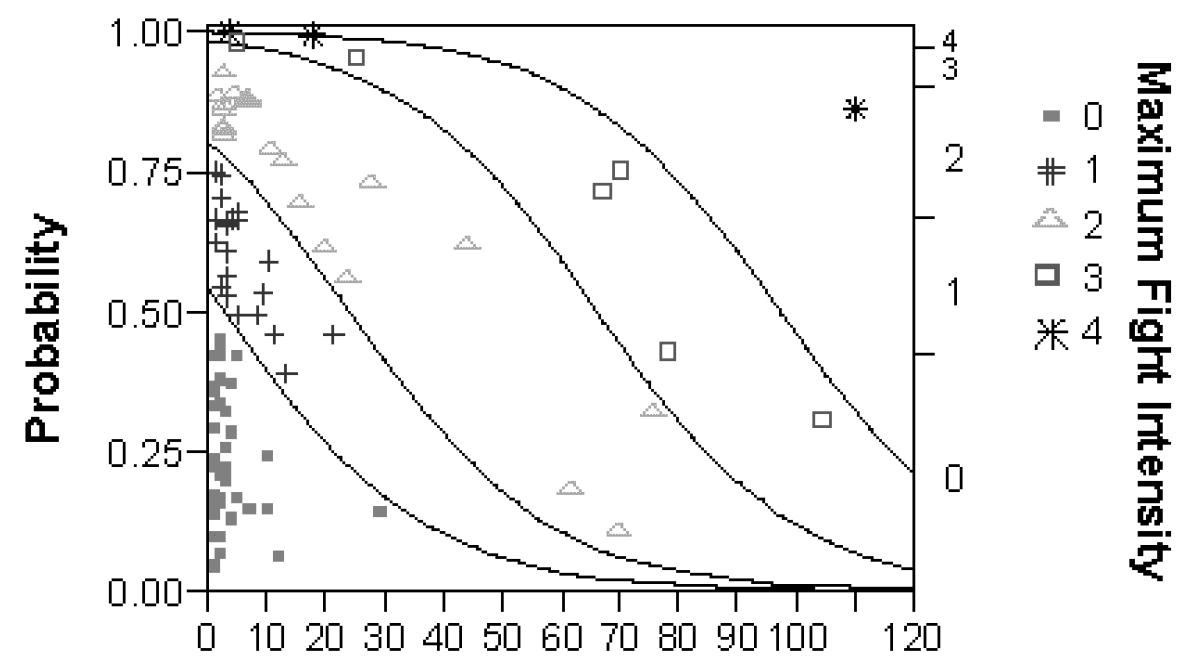

\section{Duration}

Figure 5. Fight duration vs. maximum intensity. The left $y$-axis represents probability, and the proportions shown on the right $y$-axis represents the relative sizes of each fight intensity category (0-4) in the total sample. Duration of fights on the $x$-axis is represented in seconds. At each duration value, the probability scale in the $y$-direction is divided into probabilities for each fight intensity category. The probabilities are measured as the vertical distance between the curves, and the total across all $Y$ category probabilities sum to 1 . The bottom curve shows the probability attributed to fight intensity 0 (illustrated by the marked data for intensity 0) as duration varies. The distance between the bottom curve and the curve above it is the probability for fight intensity 1 . Thus, the distance between each consecutive curve corresponds to the probability for fight intensities $0-4$ as duration varies, with fight intensity 4 represented by the top curve and above. The model indicates that probabilities for higher fight intensities increase with duration.

finds that this characterization holds also true for crayfish, and further adds that agonistic interactions indeed represent common events in the behavioural biology of Orconectes rusticus. On many occasions, intraspecific agonistic interactions were observed along the shallow edges of the river at many of the field sites. In light of the high population densities found in the present study it should be expected to see frequent incidences in which individual crayfish happen upon each other. Moreover, such estimates correspond closely to similarly high densities reported elsewhere (Momot et al., 1978; Stewart \& Haynes, 1994), suggesting that crowded conditions with frequent agonistic encounters may well be a common feature of crayfish behavioural biology, rather than an extreme and isolated case. 


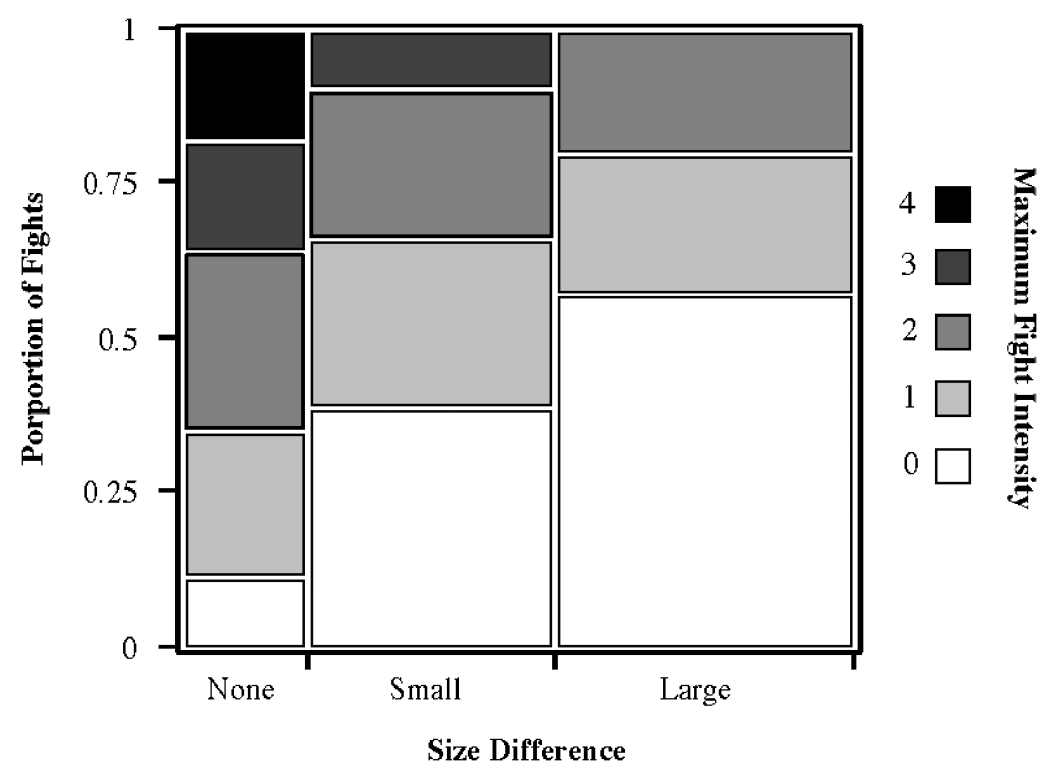

Figure 6. Fight intensity and size asymmetry of opponents. Asymmetries of body size are represented in three categories, none (within approx. 10\%), small $(30 \%>$ difference $>$ $10 \%$ ), and large (difference $>30 \%$ ). The $y$-axis on the left indicates the proportion of fights that ended at each intensity. Fight intensities 0-4 (defined in the methods) are indicated by shading.

Many aggressive interactions occurred within the context of shelter acquisition or defense. Burrows were always occupied singly and owners repeatedly returned to the same site throughout the observation period. As a common source of conflict they appear to represent valuable resources. Moreover, the availability of shelters provides a strong predictor for crayfish densities (Miller, 1985; Hill \& Lodge, 1994; Davis \& Huber, unpubl.). Such residents also spend significant amounts of time each day away from shelter in search of food. During such periods they roam the immediate vicinity, graze on algal mats, and frequently enter agonistic interactions with conspecific along the way. Surrounding shelters are explored and smaller individuals are often evicted. In one telling example, a resident animal repeatedly displaced others nearby.

Crayfish encounters in the field closely match predictions from simple game theory models (Maynard Smith \& Parker, 1976; Maynard Smith, 1982) to more complex sequential assessment models for stepwise fighting (Leimar et al., 1991). The characteristics of crayfish field encounters reported here 
closely resemble those described from laboratory settings (Huber et al., 2001a). Fights feature a set of stereotyped behaviour patterns (Bruski \& Dunham, 1987), and intensity escalates as fighting progresses (Huber \& Kravitz, 1995; Huber et al., 2001a). Prior residence (Peeke et al., 1995; Ranta \& Lindstöm, 1992, 1993), greater size (Ranta \& Lindström, 1993; Rutherford et al., 1995; Pavey \& Fielder, 1996), and previous fighting success (Issa et al., 1999; Goessmann et al., 2000) all serve as important predictors for an individual's willingness to enter and escalate a fight.

Crayfish are traditionally viewed as a predominantly nocturnal animal (Hazlett et al., 1979; Gherardi et al., 1998, 2000; Barbaresi \& Gherardi, 2001) and fish predation is believed to be a driving force in this context (Nyström, 2002). The present study supports laboratory findings that crayfish activity level and behavioural responses to predators vary with crayfish size due to differential susceptibility to predators (Stein \& Magnuson, 1976; Stein, 1977). The present study found important differences in distribution and activity patterns as a function of size. Large crayfish inhabiting the deeper sections of the river were exposed to several predatory fish species, however, they were large enough to mostly exceed their gape constraints. Terrestrial predators such as birds and mammals preferentially feed on large crayfish (Correia, 2001), but predation risk by terrestrial predators is lower in deeper water (Englund \& Krupa, 2000). Large crayfish therefore appear to reduce their predation risk by being nocturnal and inhabiting deeper water. In contrast, smaller individuals were found predominantly along the shallow edges of the river, where they experienced reduced risks from capture by fish and cannibalistic conspecifics (Alcorlo et al., 2004; Pérez-Bote, 2005), but at an increased risk of predation by a variety of avian and mammalian predators (Englund \& Krupa, 2000). At present there is no evidence that different-sized crayfish vary in their ability to detect infrared light. An apparent under-representation of small crayfish active at night could alternatively be due to higher sensitive to the infrared lighting at the observation area, although there is presently no evidence that this is indeed the case.

This non-manipulative field study provides an ethological context for the occurrence of aggression in this species. It points to the need to consider crayfish fighting behaviour within a framework of high population densities, the importance of shelters for protection from predators or conspecific cannibals, and the expression of an inherent tendency of agonism towards conspecifics. Ethological studies such as these allow us to gain a better under- 
standing of the natural behaviour of decapods and to root laboratory findings within a comprehensive behavioural and ecological framework.

\section{Acknowledgements}

We would like to thank Jeff Miner, Dan Wiegmann and Moira van Staaden for their helpful suggestions and comments. A special thanks goes to the members of the Huber lab (Jami Barnes, Katie Drereup, Karlo Hock, Jules Panksepp, Angelica Pytel, Adam Stocker) for their help during all stages of this research. Thanks also to Alisdair Daws, Matt Hoostal, Steve Queen and Karl Tatgenhorst for their technical support.

\section{References}

Alcorlo, P., Geiger, W. \& Otero, M. (2004). Feeding preference and food selection of the red swamp crayfish, Procambarus clarkii, in habitats differing in food item diversity. Crustaceana 77: 435-453.

Barbaresi, S. \& Gherardi, F. (2001). Daily activity of the white-clawed crayfish, Austropotamobius pallipes (Lereboullet): a comparison between field and laboratory studies. - $\mathrm{J}$. Nat. Hist. 35: 1861-1871.

Barki, A. \& Karplus, I. (1999). Mating behavior and a behavioral assay for female receptivity in the red-claw crayfish Cherax quadricarinatus. - J. Crust. Biol. 19: 493-497.

Bergman, D.A. \& Moore, P.A. (2003). Field observations of intraspecific agonistic behavior of two crayfish species Orconectes rusticus and Orconectes virilis in different habitats. — Biol. Bull. 205: 26-35.

Berrill, M. (1978). Distribution and ecology of crayfish in the Kawartha Lakes region of southern Ontario. - Can. J. Zool. 56: 166-177.

Berrill, M. \& Arsenault, M. (1982). Spring breeding of a northern temperate crayfish, Orconectes rusticus. — Can. J. Zool. 60: 2641-2645.

Berrill, M. \& Arsenault, M. (1984). The breeding-behaviour of a northern temperate Orconectid crayfish, Orconectes rusticus. - Anim. Behav. 32: 333-339.

Bouwma, P. \& Hazlett, B.A. (2001). Integration of multiple predator cues by the crayfish Orconectes propinquus. - Anim. Behav. 61: 771-776.

Bovbjerg, R.V. (1953). Dominance order in the crayfish Orconectes virilis (Hagen). - Physiol. Zool. 26: 173-178.

Bovbjerg, R.V. (1956). Some factors affecting aggressive behavior in crayfish. - Physiol Zool. 29: 127-136.

Brower, J.E., Zar, J.H. \& Ende, C.N.V. (1990). Field and laboratory methods for general ecology. $3^{\text {rd }}$ edn. - W. C. Brown, Dubuque, IA

Bruski, C.A. \& Dunham, D.W. (1987). The importance of vision in agonistic communication of the crayfish Orconectes rusticus I. an analysis of bout dynamics. - Behaviour 103: 83-107.

Capelli, G.M. \& Hamilton, P.A. (1984). Effects of food and shelter on aggressive activity in the crayfish Orconectes rusticus (Girard). — J. Crust. Biol. 4: 252-260. 
Cooper, R.A. \& Uzmann, J.R. (1980). Ecology of juvenile and adult Homarus. — In: The Biology and Management of Lobsters (Cobb, J.S. \& Phillips, B.F.E., eds). Academic Press, New York, NY, p. 97-142.

Correia, A.M. (2001). Seasonal and interspecific evaluation of predation by mammals and birds on the introduced red swamp crayfish Procamabarus clarkii (Crustacea, Cambaridae) in a freshwater marsh (Portugal). — J. Zool. Lond. 255: 533-541.

Creed, R.P. (1994). Direct and indirect effects of crayfish grazing in a stream community. Ecology 75: 2091-2103.

Edwards, D.H., Heitler, W.J. \& Krasne, F.B. (1999). Fifty years of a command neuron: the neurobiology of escape behavior in crayfish. - Trends Neurosci. 222: 153-160.

Englund, G. \& Krupa, J.J. (2000). Habitat use by crayfish in stream pools: influence of predators, depth and body size. - Freshwater Biol. 43: 75-83.

Figler, M.H., Blank, G.S. \& Peeke, H.V.S. (1997). Maternal aggression and post-hatch care in red swamp crayfish, Procambarus clarkii (Girard): the influences of presence of offspring, fostering, and maternal molting. - Mar. Fresh. Behav. Physiol. 30: 173-194.

Figler, M.H., Blank, G.S. \& Peeke, H.V.S. (2001). Maternal territoriality as an offspring defense strategy in red swamp crayfish (Procambarus clarkii, Girard). - Aggres. Behav. 27: 391-403.

Figler, M.H., Blank, G.S. \& Peeke, H.V.S. (2005). Shelter competition between resident male red swamp crayfish Procambarus clarkia (Girard) and conspecific intruder varying by sex and reproductive status. - Mar. Fresh. Behav. Physiol. 38: 237-248.

Flinders, C.A. \& Magoulick, D.D. (2006). Distribution, habitat use, and life history of streamdwelling crayfish in the spring river drainage of Arkansas and Missouri with a focus on the imperiled Mammoth Spring crayfish (Orconectes marchandi). - Am. Midl. Nat. 154: 358-374.

Gherardi, F. \& Barbaresi, S. (2000). Invasive crayfish: activity patterns of Procambarus clarkii in the rice fields of the lower Guadalquivir (Spain). — Arch. Hydrobiol. 150: 153-168.

Gherardi, F., Barbaresi, S. \& Salvi, G. (2000). Spatial and temporal patterns in the movement of Procambarus clarkii, an invasive crayfish. — Aquat. Sci. 62: 179-193.

Gherardi, F., Barbaresi, S. \& Villanelli, F. (1998). Movement patterns of the white-clawed crayfish, Austropotamobius pallipes, in a Tuscan Stream. - J. Fresh. Ecol. 13: 413424.

Goessmann, C., Hemelrijk, C. \& Huber, R. (2000). The formation and maintenance of crayfish hierarchies: behavioral and self-structuring properties. - Behav. Ecol. Sociobiol. 48: 418-428.

Guiasu, R.C. \& Dunham, D.W. (1998). Inter-form contest in male crayfishes, Cambarus robustus (Decapoda, Cambaridae). - Invert. Biol. 117: 144-154.

Guiasu, R.C., Barr, D.W. \& Dunham, D.W. (1996). Distribution and status of crayfishes of the genera Cambarus and Fallicambarus (Decapoda: Cambaridae) in Ontario, Canada. — J. Crust. Biol. 16: 373-383.

Hamr, P. \& Berrill, M. (1984). The life histories of north-temperate populations of the crayfish Cambarus robustus and Cambarus bartoni. - Can. J. Zool. 63: 2313-2322.

Hazlett, B. (1983). Parental behavior in decapod crustacea. - In: Studies of Adaptation: the Behavior of Higher Crustaceans (Rabach, S. \& Dunham, R.S., eds). Wiley, New York, NY, p. 171-193. 
Hazlett, B., Rittschof, D. \& Ameyaw-Akumfi, C. (1979). Factors affecting the daily movements of the crayfish Orconectes virilis (Hagen, 1870) (Decapoda, Cambaridae). Crustaceana Suppl. 5: 121-130.

Hazlett, B., Rittschof, D. \& Rubenstein, D. (1974). Behavioral biology of the crayfish Orconectes virilis I. home range. - Am. Midl. Nat. 92: 301-311.

Hazlett, B., Rubenstein, D. \& Rittschof, D. (1975). Starvation, energy reserves, and aggression in the crayfish Orconectes virilis (Hagen, 1870) (Decapoda, Cambaridae). - Crustaceana 28: 11-16.

Herberholz, J., Sen, M.M. \& Edwards, D.H. (2004). Escape behavior and escape circuit activation in juvenile crayfish during prey-predator interactions. - J. Exp. Biol. 207: 1855-1863.

Herrick, F.H. (1909). The natural history of the American lobster. - Bull. U.S. Bur. Fish. 29: 149-408.

Hill, A.M. \& Lodge, D.M. (1994). Diel changes in resource demand - competition and predation in species replacement among crayfishes. - Ecology 75: 2118-2126.

Huber, R. \& Delago, A. (1998). Serotonin alters decisions to withdraw in fighting crayfish, Astacus astacus: the motivational concept revisited. - J. Comp. Physiol. A. Sens. Neural Behav. Physiol. 182: 573-583.

Huber, R. \& Kravitz, E.A. (1995). A Quantitative-analysis of agonistic behavior in juvenile american lobsters (Homarus americanus). - Brain Behav. Evol. 46: 72-83.

Huber, R., Daws, A.G., Tuttle, S.A. \& Panksepp, J.B. (2001a). Quantitative behavioral techniques for the study of crustacean aggression. - In: The Crustacean Nervous System (Wiese, K., ed.). Springer, Berlin, p. 186-203.

Huber, R., Panksepp, J.B., Yue, Z., Delago, A. \& Moore, P. (2001b). Dynamic interactions of behavior and amine neurochemistry in acquisition and maintenance of social rank in crayfish. - Brain Behav. Evol. 57: 271-282.

Issa, F.A., Adamson, D.J. \& Edwards, D.H. (1999). Dominance hierarchy formation in juvenile crayfish Procambarus clarkii. - J. Exp. Biol. 202: 3497-3506.

Kawai, T. \& Saito, K. (2001). Observations on the mating behavior and season, with no form alternation, of the Japanese crayfish, Cambaroides japonicus (Decapoda, Cambaridae), in lake Komadome, Japan. — J. Crust. Biol. 21: 885-890.

Leimar, O., Austad, S. \& Enquist, M. (1991). A test of sequential assessment game: fighting in the bowl and doily spider Frontinella pyramitela. — Evolution 45: 862-874.

Levi, T., Barki, A., Hulata, G. \& Karplus, I. (1999). Mother-offspring relationships in the red-claw crayfish Cherax quadricarinatus. - J. Crust. Biol. 19: 477-484.

Mason, J.C. (1970). Copulatory behavior of the crayfish, Pacifastacus trowbridgii (Stimpson). - Can. J. Zool. 48: 969-976.

Maynard Smith, J. (1982). Evolution and the Theory of Games. - Cambridge University Press, Cambridge.

Maynard Smith, J. \& Parker, G.A. (1976). The logic of asymmetric contests. - Anim. Behav. 24: $159-175$

Miller, C. (1985). Correlates of habitat favorability for benthic macroinvertebrates at 5 stream sites in an Appalachian mountain drainage-basin, USA. — Freshwater Biol. 15: 709733.

Momot, W.T. (1967). Population dynamics and productivity of the crayfish, Orconectes virilis, in a marl lake. Am. Midl. Nat. 78: 55-81. 
Momot, W.T. (1995). Redefining the role of crayfish in aquatic ecosystems. — Rev. Fish. Sci. 3: 33-63.

Momot, W.T., Gowing, H. \& Jones, P.D. (1978). The dynamics of crayfish and their role in ecosystems. - Am. Midl. Nat. 99: 10-35.

Mulloney, B. \& Hall, W.M. (1991). Neurons with histamine like immunoreactivity in the segmental and stomatogastic nervous systems of the crayfish Pacifastacus lenisusculus and the lobster Homarus americanus. - Cell Tissue Res. 266: 197-207.

Mulloney, B., Harness, P.I. \& Hall, W.M. (2006). Burst of information: Coordination interneurons encode multiple parameters of a periodic motor pattern. - J. Neurophysiol. 95: 850-861.

Nyström, P. (2002). Ecology. — In: Biology of Freshwater Crayfish (Holdich, D.M., ed.). Backwell Science, Oxford, p. 192-235.

Panksepp, J.B., Yue, Z., Drerup, C. \& Huber, R. (2003). Amine neurochemistry and aggression in crayfish. - Microsc. Res. Tech. 60: 360-368.

Parkyn, S.M., Collier, K.J. \& Hicks, B.J. (2001). New Zealand stream crayfish: functional omnivores but trophic predators? - Freshwater Biol. 46: 641-652.

Pavey, C.R. \& Fielder, D.R. (1996). The Influence of size differential on agonistic behaviour in the freshwater crayfish, Cherax cuspidatas (Decapoda: Parastacidae). J. Zool. 238: 445-457.

Peeke, H.V.S., Sippel, J. \& Figler, M.H. (1995). Prior residence effects in shelter defense in adult signal crayfish (Pacifastacus leniusculus (Dana)) - results in same-sex and mixedsex dyads. - Crustaceana 68: 873-881.

Pérez-Bote, J.L. (2005). Feeding ecology of the exotic red swamp crayfish, Procambarus clarkii (Girard, 1852) in the Guadiana River (SW Iberian Peninsula). - Crustaceana 77: 1375-1387.

Ranta, E. \& Lindström, K. (1992). Power to hold sheltering burrows by juveniles of the signal crayfish, Pasifastacus leniusculus. — Ethology 92: 217-226.

Ranta, E. \& Lindström, K. (1993). Body-size and shelter possession in mature signal crayfish, Pacifastacus leniusculus. - Ann. Zool. Fenn. 30: 125-132.

Renz, M. \& Breithaupt, T. (2000). Habitat use of the crayfish Austropotamobius torrentium in small brooks and in Lake Constance, southern Germany. - Bull. Fr. Peche Piscic. 356: 139-154.

Rubenstein, D.I. \& Hazlett, B.A. (1974). Examination of the agonistic behaviour of the crayfish Orconectes virilis by character analysis. - Behaviour 50: 193-216.

Rutherford, P.L., Dunham, D.W. \& Allison, V. (1995). Winning agonistic encounters by male crayfish Orconectes rusticus (Girard) (Decapoda, Cambaridae) - chela size matters but chela symmetry does not. - Crustaceana 68: 526-529.

Schroeder, L. \& Huber, R. (2001). Fight strategies differ with size and allometric growth of claws in crayfish, Orconectes rusticus. - Behaviour 138: 1437-1449.

Stein, R.A. (1977). Selective predation, optimal foraging, and the predator-prey interaction between fish and crayfish. - Ecology 58: 1237-1253.

Stein, R.A. \& Magnuson, J.J. (1976). Behavioral response of crayfish to a fish predator. Ecology. 57: 751-761.

Stewart, T.W. \& Haynes, J.M. (1994). Benthic macroinvertebrate communities of southwestern Lake Ontario following invasion of Dreissena. - J. Great Lakes Res. 20: 479-493.

Stocker, A.M. \& Huber, R. (2001). Fighting strategies in crayfish Orconectes rusticus (Decapoda, Cambaridae) differ with hunger state and the presence of food cues. - Ethology $107: 727-736$ 
Tierney, A.J. (2003). Introduction to the crayfish nervous system: from histology to function. Microsc. Res. Tech. 60: 251-252.

Usio, N. \& Townsend, C.R. (2000). Distribution of the New Zealand crayfish Paranephrops zealandicus in relation to stream physico-chemistry, predatory fish, and invertebrate prey. - N.Z. J. Mar. Fresh. Res. 34: 557-567.

Westin, L. \& Gydemo, R. (1988). The locomotor-activity patterns of juvenile noble crayfish (Astacus-astacus) and the effect of shelter availability. - Aquaculture 68: 361-367.

White, G.C., Anderson, D.R., Burnham, K.P. \& Otis, D.L. (1982). Capture-recapture and removal methods for sampling closed populations. - National Laboratory, Los Alamos, NM. 